\title{
Isoconversional Model of Kinetics of Thermally Induced Processes in Chalcogenide Glass $\mathrm{Sb}_{37} \mathrm{~S}_{48} \mathrm{I}_{15}$
}

\author{
R.R. RAONIĆ* ${ }^{*}$ N.M. ĆELIĆ, \\ S.R. Lukić-Petrović And G.R. ŠTrbaC
}

University of Novi Sad, Faculty of Sciences, Department of Physics, Trg Dositeja Obradovića 4, 21000 Novi Sad, Serbia

Received: 02.06.2021 \& Accepted: 01.09.2021

\begin{abstract}
In this paper, we have made isoconversional modeling and analyses of kinetics of thermally induced processes for $\mathrm{Sb}_{37} \mathrm{~S}_{48} \mathrm{I}_{15}$ chalcogenide glass. The non-isothermal differential scanning calorimetry was used and for four different heating rates the corresponding curves were obtained with this method. The change in the apparent activation energy with the extent of conversion for three thermally induced processes (glass transition, crystallization and melting) was analyzed by using two different isoconversional methods - the isoconversional form of Kissinger model and the Vyazovkin method. The values of activation energy during the glass transition indicated the domination of cooperative movements of structural units while the decrease of this parameter with temperature (the extent of conversion) implied that these movements are becoming freer. The found dynamic fragility index value of $m=23.2(10)$ indicated that significant configuration changes are not present near the glass transition temperature. Crystallizations of two structural units, SbSI and $\mathrm{Sb}_{2} \mathrm{~S}_{3}$, were detected. For SbSI, the activation energy increased from $E_{\alpha}=103 \mathrm{eV}$ for the extent of conversion of $\alpha=5 \%$ to $E_{\alpha}=162 \mathrm{eV}$ for the extent of conversion of $\alpha=95 \%$. This is related to the influence of the initial stage of parallel crystallization of the new structural unit $\mathrm{Sb}_{2} \mathrm{~S}_{3}$. Activation energy for crystallization of $\mathrm{Sb}_{2} \mathrm{~S}_{3}$ changed from $E_{\alpha}=140 \mathrm{eV}$ to $E_{\alpha}=167 \mathrm{eV}$ for the same values of the extent of conversion. A small change in energy indicates a volume nucleation with a constant number of nuclei. The isoconversional analysis of melting of SbSI has shown that the activation energy decreased with the extent of conversion from $E_{\alpha}=526 \mathrm{eV}(\alpha=4 \%)$ to $E_{\alpha}=341 \mathrm{eV}(\alpha=96 \%)$ and that it was not a single-step process. The results from both applied methods were in agreement.
\end{abstract}

topics: heat capacity, crystallization, glass transitions, differential thermal analysis (DTA)

\section{Introduction}

Chalcogenide glasses have attracted great attention over the years and have often been the subject of research because of their interesting properties which make them attractive for different applications. These applications include materials for electronic elements in telecommunication systems [1] such as devices tailored for high speed signal processing [2], infrared materials for night vision [3], electrical switching phenomenon which can potentially be used for information storage, power control, phase change memories (PCM) [4] and many more. They are primarily investigated for their optical and electrical qualities (optical parameters such as optical band gap and refractive index, transparency in visible and infrared spectrum, electrical conductivity) $[1,5-8]$. If they are alloyed with certain elements, their properties can significantly change and application possibilities are particularly increased [9-15].

Specifically, chalcogenide glasses containing $\mathrm{Sb}$ are of importance because of their potential applications in thermal imaging, nonlinear optics and lasers [16]. Their thermal properties (thermal stability and glass forming ability) can vary with $\mathrm{Sb}$ concentration [17]. Some chemical elements, among which is $\mathrm{Sb}$, are found to modify chalcogenide glasses at the nanoscale, inducing significant changes in their physical properties and making those chalcogenide alloys attractive materials for many applications, including (nano)optics and (nano)electronics [18-21]. Several researches have reported that the potential candidates for new generation narrow-bandgap media can be engineered on the basis of chalcogenide glasses (ChGs) modified at 
the nanoscale by $\mathrm{Bi}, \mathrm{Sb}$, and $\mathrm{Ga}$ dopants [22-24]. The $\mathrm{Bi}$ and $\mathrm{Sb}$ are even reported to convert some chalcogenide glasses generally highly insensitive to metal doping into n-type semiconductors [25, 26]. All of the above applications rest on the effects of formation of ordered regions of desired size and concentration in the amorphous matrix by modifying the process of their synthesis or using external impacts, such as thermal treatment [27].

For chalcogenide glasses containing $\mathrm{Sb}$, there is a possibility of thermal induction of ferroelectric centers SbSI, which makes them promising glassceramics materials for future applications. Some antimony sulphoiodide (SbSI) properties distinguish this chalcogenide compound from other ferroelectrics and make it suitable for use in uncooled pyrooptic and pyroelectric infrared detectors: high values of the dielectric constant, spontaneous polarization, and pyroelectric and pyrooptic coefficients [28-30]. Consequently, examination of thermally induced processes in chalcogenide glasses containing $\mathrm{Sb}$ is of large importance. As it is usually the case, all these properties are highly dependent on the preparation conditions and ratio of their components.

Unfortunately, Sb-S-I type glasses can be obtained in a relatively narrow range of ratios of concentrations by the cooling method and the stoichiometric composition of the ferroelectric SbSI compound lies outside of the $\mathrm{Sb}-\mathrm{S}-\mathrm{I}$ system glassforming region. Investigations of the existence of the glass phase in the three-component $\mathrm{Sb}-\mathrm{S}-\mathrm{I}$ system [31] have determined that compact glass can be obtained in a narrow area, of an island character, in the vicinity of the composition $\mathrm{Sb}_{37} \mathrm{~S}_{48} \mathrm{I}_{15}$. The phase diagram from this system was determined by Turjanica and Koperles [32].

In this paper, thermally induced processes are analyzed using an isoconversional model. Isoconversional analysis provides a deeper insight into the nature of the glasses themselves. In terms of the chemical nature of glass, there are two extremes: molecular liquids with weak isotropic forces and strong liquids with dominant covalent networks characterized by strong directional bonds. These two extreme configurations exhibit very different molecular motions and configuration changes during the glass transition process. The molecular liquids are usually modeled as continuum characterized by mean isotropic force field in which an increase of free-volume significantly facilitates the movement of structural units. On the other hand, strong liquids have rigid covalent bonds and well-defined short-range in which breaking of covalent bonds dominates the structural units' motions [33]. Based on the values of the fragility parameter, $m$, previous analyses of the kinetics of thermally induced processes in the examined glass $[34,35]$ and other glasses from the same system, it was shown that these glasses do not exhibit large configuration changes right above the glass transition temperature. According to Angell's theory, they do not belong to the strong liquids, for which $m \approx 16$ [36, 37].

\section{Experiment}

According to the protocol by which the syntheses of the other glasses from the system were done earlier $[34,35]$, the investigated $\mathrm{Sb}_{37} \mathrm{~S}_{48} \mathrm{I}_{15}$ glass was prepared using the melt-quenching technique. The sample was synthesized from elementary components of purity starting from 99.99\%, manufactured by Sigma-Aldrich. The measured masses were based on the calculations for the synthesis of $8 \mathrm{~g}$ of the sample, and analytical balance METTLER B-6 with the accuracy of $\pm 5 \times 10^{-8} \mathrm{~kg}$ was used. The samples were placed and sealed in cylindrical quartz ampoules, and evacuated to a pressure of $10^{-3} \mathrm{~Pa}$. They were then exposed to a cascade heating temperature program and air-quenched.

The heating rate in the first stage was $100 \mathrm{~K} / \mathrm{h}$. After heating the elementary components from room temperature to $473 \mathrm{~K}$, they were maintained on that temperature plateau for the next $4 \mathrm{~h}$. In all other stages, heating rates were $50 \mathrm{~K} / \mathrm{h}$, and the next two plateaus were at $673 \mathrm{~K}$ and $823 \mathrm{~K}$ with the retention of $3 \mathrm{~h}$. The last plateau corresponds to a maximum synthesis temperature of $923 \mathrm{~K}$ and at this temperature the ampoule was maintained for more than $12 \mathrm{~h}$. From this maximum synthesis temperature, the ampoule was taken out into the air, and then placed in a thermally inert material $\left(\mathrm{Al}_{2} \mathrm{O}_{3}\right.$ powder $)$ for annealing and reducing of mechanical stresses in the material.

The differential scanning calorimetry (DSC) measurement was done using a Mettler Toledo 822 device, which is operational from room temperature to $973 \mathrm{~K}$, with temperature measurement precision of $0.2 \mathrm{~K}$. Samples with mass of about $10 \mathrm{mg}$ were placed in aluminium pans (volume of pans was $40 \mu \mathrm{l}$ ) and measurements were done for four different heating rates, in the nitrogen atmosphere. Nitrogen flow during measurement was $50 \mathrm{ml} / \mathrm{min}$. The samples were selected to have at least one flat surface, in order to enable contact with the bottom of the pan, and through it, with the ceramic FRS5 sensor of the device. The obtained DSC curves were further analyzed using the Star Software. Mathematical analysis of the obtained data was done in Wolfram Mathematica and Origin programs.

In order to confirm the crystallized structural units after exposing the sample to the appropriate temperature program, an X-ray diffraction spectrum was recorded. The XRD was carried out using Rigaku MiniFlex 600 instrument, with $\mathrm{Cu} K_{\alpha}$ radiation.

Thermally induced processes by DSC were considered using the isoconversional analysis. The relation that describes the rate of thermally stimulated processes is [38, 39] 


$$
\frac{\mathrm{d} \alpha}{\mathrm{d} t}=k(T) f(\alpha)=A \exp \left(-\frac{E_{\alpha}}{R T}\right) f(\alpha),
$$

where $\alpha$ stands for the extent of conversion, $t$ is the time, $k(T)$ is the rate constant and $f(\alpha)$ is the reaction model. The rate constant can be written in the form of Arrhenius equation, where $A$ is the pre-exponential factor, $E_{\alpha}$ is the activation energy, $R$ is the universal gas constant, and $T$ is the temperature. The extent of conversion can be defined as the ratio of the current change in heat, and the total heat change during the observed process.

The basic principle for isoconversional methods is the following: the rate of the process, for a constant extent of conversion, is a function of temperature only. This allows the elimination of a reaction model from the starting equation.

The starting equation (1) can be represented in the integral form as

$$
g(\alpha)=\int_{0}^{\alpha} \frac{\mathrm{d} \alpha}{f(\alpha)}=A \int_{0}^{t} \mathrm{~d} t \exp \left(-\frac{E}{R T}\right),
$$

where for temperature raised at a constant rate $T=T_{0}+\beta t$ ( $\beta$ is the heating rate, $t$ is the time, and $T_{0}$ is the starting temperature for $t=0$ ), the integration over time can be replaced with integration over temperature

$$
g(\alpha)=\frac{A}{\beta} \int_{T_{0}}^{T} \mathrm{~d} T \exp \left(-\frac{E}{R T}\right)=\frac{A}{\beta} I(E T),
$$

where $I(E, T)$ is the temperature integral which is often approximated in different ways.

The Kissinger-Akahira-Sunose (KAS) isoconversional method [40, 41] uses an approximation of the temperature integral (3) given by Coats and Redfern [42]

$$
\begin{aligned}
& \ln \left(\frac{\beta_{i}}{T_{\alpha, i}^{2}}\right)=\ln \left(\frac{R A}{E_{\alpha} g(\alpha)}\right)-\frac{E_{\alpha}}{R T_{\alpha, i}}= \\
& \text { const. }-\frac{E_{\alpha}}{R T_{\alpha, i}},
\end{aligned}
$$

where a linear function between $\ln \left(\beta_{i} /\left(T_{\alpha, i}^{2}\right)\right.$ and $1 / T_{\alpha, i}$ is gained for each $\alpha$. The index $i$ identifies an individual heating rate. The slope of the function is equal to the current activation energy value.

The Vyazovkin isoconversional method is based on finding the minimum of the difference between two terms of the equation $[43,44]$

$$
\left|\sum_{i=1}^{n} \sum_{j \neq i}^{n} \frac{I\left(E_{\alpha}, T_{\alpha, i}\right) \beta_{j}}{I\left(E_{\alpha}, T_{\alpha, j}\right) \beta_{i}}-n(n-1)\right|=\min
$$

where $n$ is the number of different heating rates. The difference moves towards a minimal value when the left term of the equation reaches minimum

$$
\Phi\left(E_{\alpha}\right)=\sum_{i=1}^{n} \sum_{j \neq i}^{n} \frac{I\left(E_{\alpha}, T_{\alpha, i}\right) \beta_{j}}{I\left(E_{\alpha}, T_{\alpha, j}\right) \beta_{i}}=\min .
$$

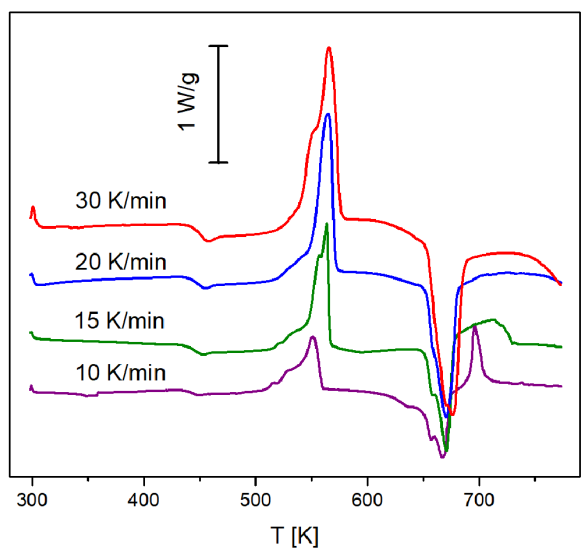

Fig. 1. DSC curve for $\mathrm{Sb}_{37} \mathrm{~S}_{48} \mathrm{I}_{15}$ glass system at four different heating rates.

The minimum is found for each extent of conversion value, which corresponds to the activation energy. For the calculation of temperature integral, the Gorbachev approximation is used [45]

$$
\begin{gathered}
I(E, T)=\int_{0}^{T} \mathrm{~d} T \exp \left(-\frac{E}{R T}\right)= \\
\frac{R T^{2}}{E}\left(\frac{1}{1+\frac{2 R T}{E}}\right) \mathrm{e}^{-E /(R T)} .
\end{gathered}
$$

\section{Results and discussion}

The obtained DSC curves for $\mathrm{Sb}_{37} \mathrm{~S}_{48} \mathrm{I}_{15}$ glass are shown in Fig. 1. Three different peaks can be observed: endothermic peak at about $450 \mathrm{~K}$, complex exothermic peak at $560 \mathrm{~K}$ and complex endothermic peak at about $670 \mathrm{~K}$. These peaks correspond to, respectively, processes of glass transition, crystallization of different structural units within the glass, and melting.

\subsection{Glass transition}

The extent of conversion as a function of temperature was determined (see Fig. 2) and the activation energies for each values of the extent were calculated. The calculations were made in Wolfram Mathematica by using the Kissinger and Vyazovkin linear isoconversional methods, namely with (4) and (6), (and the Gorbachev approximation (7)).

Figure 3 shows the decrease of apparent activation energy with extent of conversion and temperature and shows a typical behavior for most glasses. Both methods of calculation give approximately the same values. Considering the fact that activation energies are high in the initial stage (in the order of magnitude of hundreds of $\mathrm{kJ} / \mathrm{mol}$ ), this part of the glass transition process is described in terms of $\alpha$-relaxation ( $\alpha$-processes), which is characterized by a cooperative movement of molecules and structural units. In the second part of the curve, 


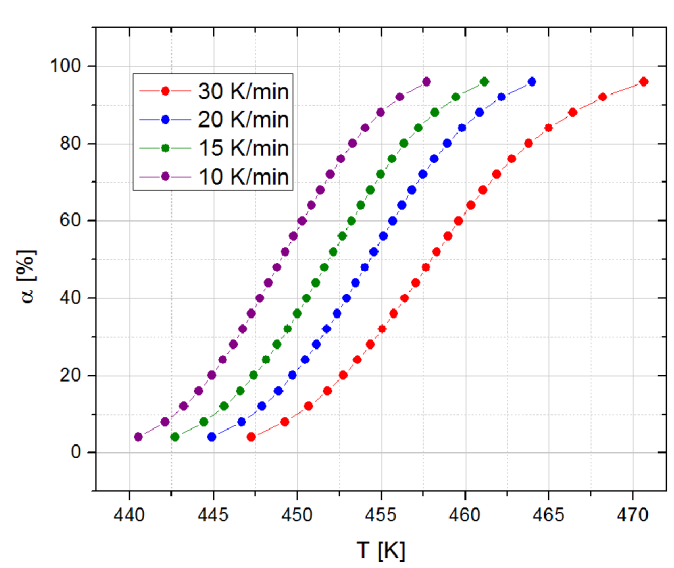

Fig. 2. The extent of conversion as a function of temperature for glass transition process.
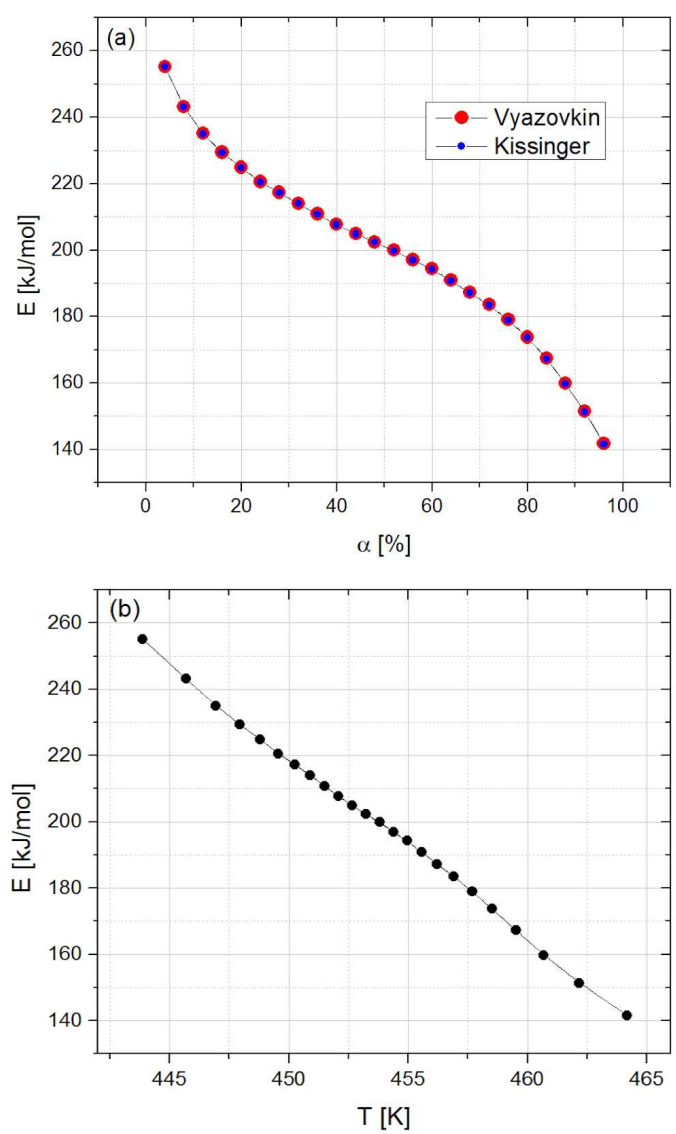

Fig. 3. Activation energy change with the extent of conversion (a) and temperature (b) for glass transition process.

the activation energies drop to twice lower values. As the process carries on, free volume grows, the rearrangement of structural units becomes easier and they begin to move in non-cooperative manner.

The use of non-isoconversional methods on the investigated glass has revealed that the values of activation energy for onset glass transition temperature are about $300 \mathrm{~kJ} / \mathrm{mol}$ [34]. Considering that glass transition temperature defined in this way corresponds to a small extent of conversion (it represents the initial stage of glass transition), the values obtained through isoconversional methods are in good agreement.

Dynamic fragility parameter of the glass is also determined by using

$$
m=\frac{E_{g}}{\ln 10 R T_{g}},
$$

where $E_{g}$ is the apparent activation energy of glass transition and $T_{g}$ is the glass transition temperature. The fragility parameter can be estimated with (8), whereby values that correspond to a conversion rate of $\alpha=0.5$ can be selected for the activation energy and the glass transition temperature (see Fig. 3). The obtained value was $m=23.2(10)$ and it indicates that this glass does not undergo significant configuration changes near glass transition temperature, but still cannot be considered as a strong melt.

\subsection{Crystallization}

As it can be seen from the shapes of crystallization peaks in Fig. 1, crystallization of this chalcogenide glass is a complex process. Based on the position of the melting peaks of the crystallized units (as it will be shown later) and analyses in similar systems [46], it can be separated into two different processes - crystallization of $\mathrm{SbSI}$ and $\mathrm{Sb}_{2} \mathrm{~S}_{3}$ structural units. Deconvolution of peaks was made before isoconversional analysis. The small exothermic effect that can be detected at low heating rates probably corresponds to the change in the crystallization mechanism. The energy of such transformation is small, i.e., the crystallization of SbSI is extremely dominant, hence the deconvolution of these two processes within the first peak was not made.

The dependence of the extent of conversion on temperature for the first peak (see Fig. 4) was used to determine $T_{\alpha}$ for each $\alpha$.

The change of activation energy with the extent of conversion and temperature for the first peak is shown in Fig. 5.

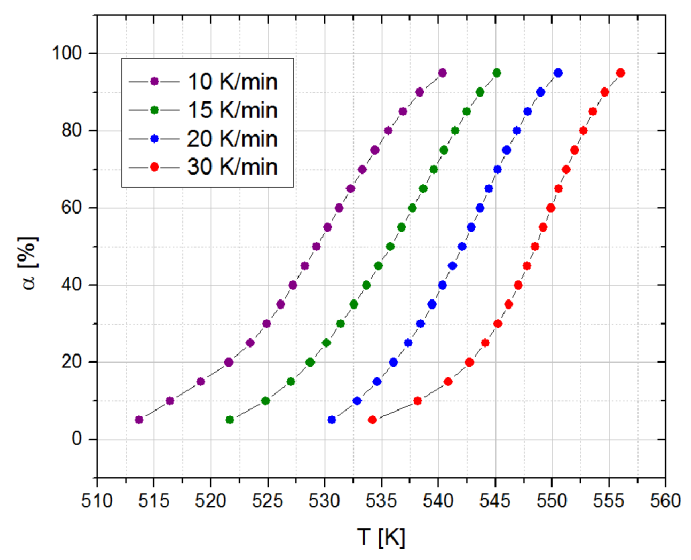

Fig. 4. The extent of conversion as a function of temperature for the first peak of crystallization. 

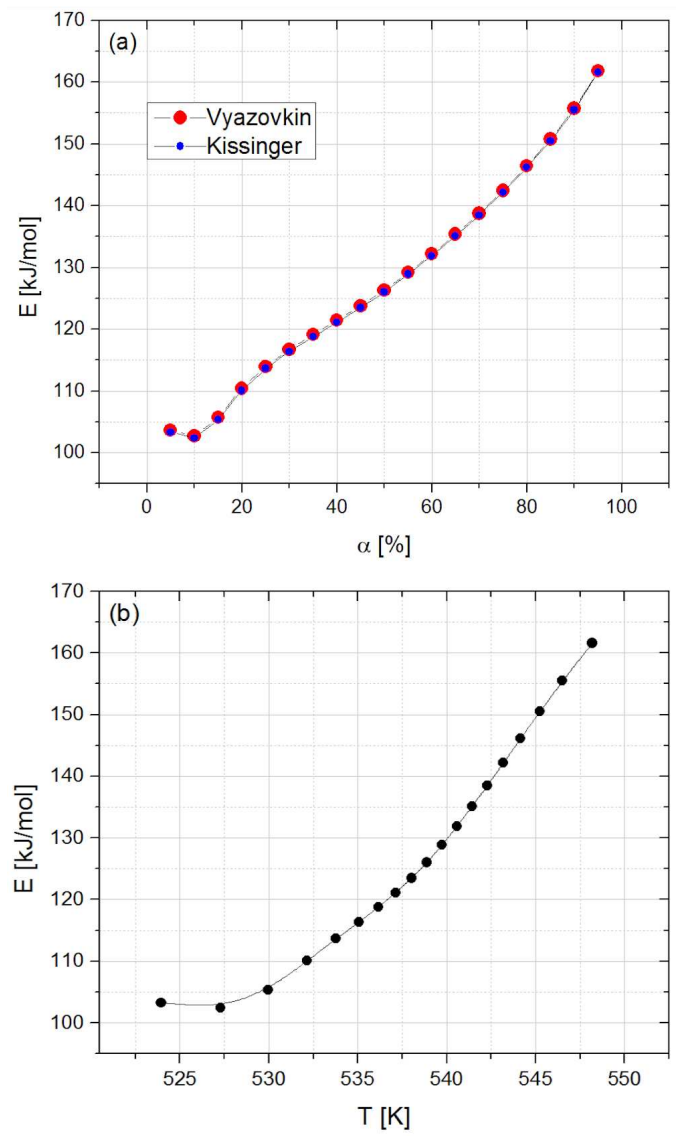

Fig. 5. Activation energy change with the extent of conversion (a) and temperature (b) for the first peak of crystallization.

The application of different non-isoconversional models has shown that for this glass, crystallization of SbSI structural unit occurs through volume nucleation and three-dimensional growth, but the number of centers of crystallization does not change significantly during the experiment [34]. The change in activation energy is unexpectedly large considering that most of the energy should be associated with crystal growth. The increase of $E_{\alpha}$ with the extent of conversion can be explained by the influence of the initial stage of parallel crystallization of the new structural unit $\mathrm{Sb}_{2} \mathrm{~S}_{3}$. The activation energy for peak maximum $E_{\alpha}=130 \mathrm{~kJ} / \mathrm{mol}$ obtained through other, non-isoconversional methods [34] is in accordance with the value obtained by using the Vyazovkin and Kissinger isoconversional method of $E_{\alpha}=126 \mathrm{~kJ} / \mathrm{mol}$ (for the extent of conversion $\alpha=0.5$, which approximately corresponds to crystallization maximum).

The relevant graphs for the second peak of crystallization of $\mathrm{Sb}_{37} \mathrm{~S}_{48} \mathrm{I}_{15}$ chalcogenide glass are shown in Figs. 6 and 7.

The second peak corresponds to crystallization of the $\mathrm{Sb}_{2} \mathrm{~S}_{3}$ structural unit. Taking into consideration that - at lower values of the extent of conversion - two parallel crystallizations take place, and analyzing from the moment where only the $\mathrm{Sb}_{2} \mathrm{~S}_{3}$

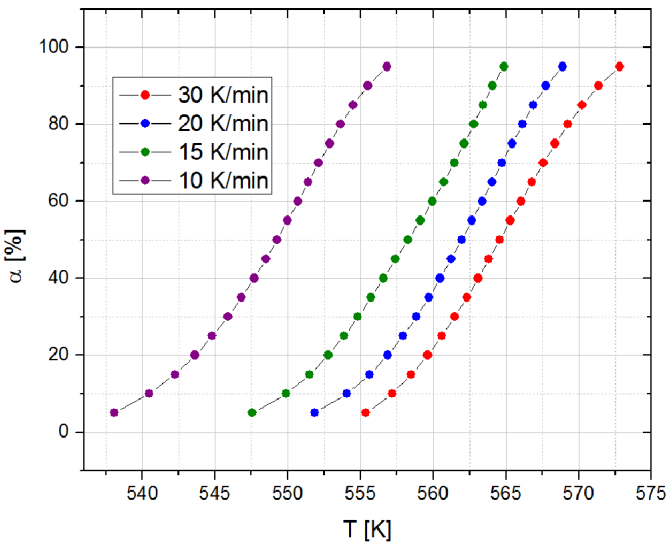

Fig. 6. The extent of conversion as a function of temperature for the second peak of crystallization.
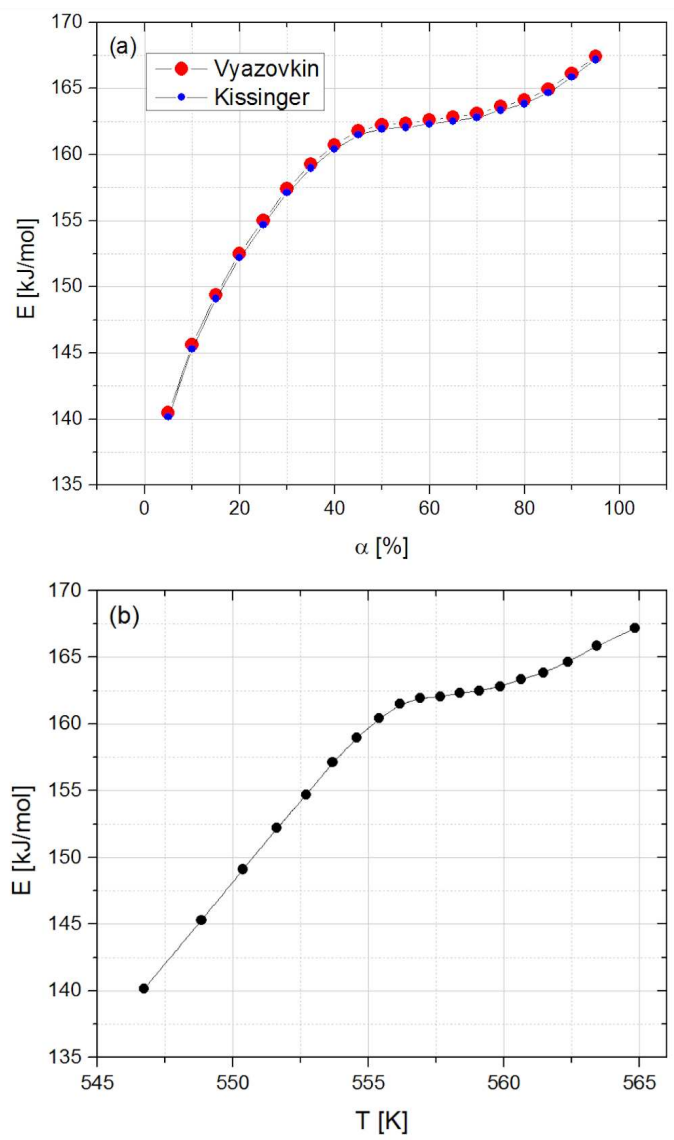

Fig. 7. Activation energy change with the extent of conversion (a) and temperature (b) for the second peak of crystallization.

structural unit crystallizes, the change in activation energy is under $10 \%$, so the activation energy can therefore be considered approximately constant.

Earlier analyses of glasses with antimony [34] have shown that for this composition for crystallization of this structural unit there is, again, a volume nucleation with a constant number of nuclei. The activation energy does not refer to nucleation, but mostly to crystal growth and therefore 
significant changes in the activation energy were not to be expected [47]. The fact that activation energy does not change significantly provides a confirmation of validity of application of different non-isoconversional methods in the analysis of crystallization mechanisms, which are based on the assumption that the activation energy is constant. In this case, there is a good accordance of the values of activation energy obtained through non-isoconversional methods for crystallization peak $(\sim 170 \mathrm{~kJ} / \mathrm{mol}[34])$ and isoconversional methods $E_{\alpha=0.5}=162 \mathrm{~kJ} / \mathrm{mol}$.

\subsection{Melting}

Melting of $\mathrm{Sb}_{37} \mathrm{~S}_{48} \mathrm{I}_{15}$ is, like crystallization, a complex process, consisting of more than one transformation. The process was separated into two different peaks. A small endothermic effect, noticeable at low heating rates, could be a confirmation of the observed transformation within crystallization of SbSI. In the recorded peaks, at $\sim 670 \mathrm{~K}$, there is a domination of melting of the crystallized SbSI structural unit.

The relevant graphs for the peak of melting of SbSI are shown in Figs. 8 and 9. A characteristic, expected decrease of activation energy with temperature is observed, which is noticed in other materials as well [48]. Values obtained through both applied methods are in accordance. The activation energy changes from $E_{\alpha}=526 \mathrm{eV}(\alpha=4 \%)$ to $E_{\alpha}=341 \mathrm{eV}(\alpha=96 \%)$. The activation energy change is $30 \%$, which implies that this is a complex, not a single-step process. If we compare melting temperatures observed in our experiment $(T=667.20(20) \mathrm{K}$ at heating rate of $10 \mathrm{~K} / \mathrm{min})$ and in [49] $(T=665.15 K)$, they are in accordance, which is a confirmation of crystallization and melting of this structural unit.

As it can be found in literature [49], melting of $\mathrm{Sb}_{2} \mathrm{~S}_{3}$ occurs at significantly higher temperatures $(T=823.15 \mathrm{~K})$. However, the thermal decomposition of the material starts at temperatures higher

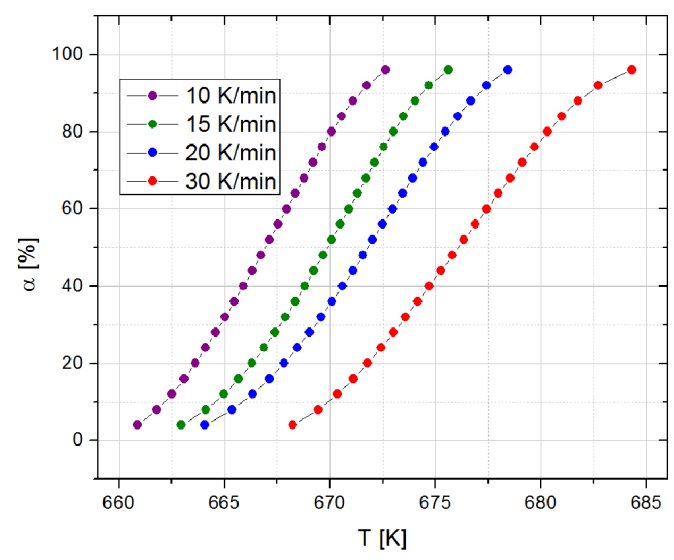

Fig. 8. The extent of conversion as a function of temperature for the peak of melting.
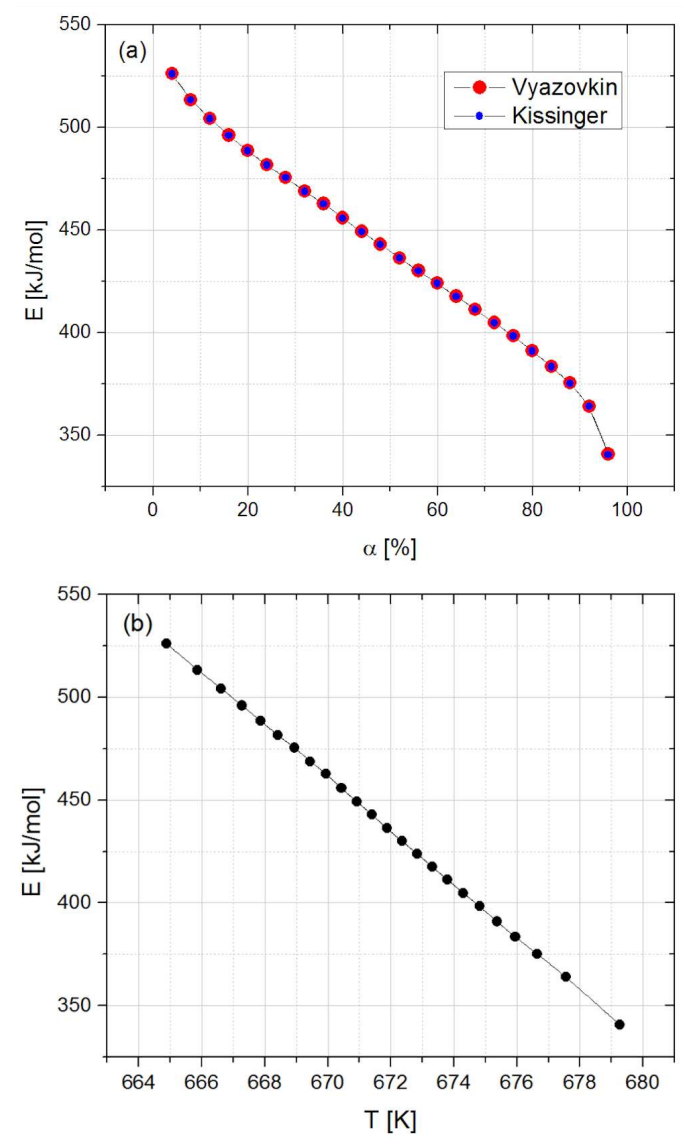

Fig. 9. Activation energy change with the extent of conversion (a) and temperature (b) for the peak of melting.

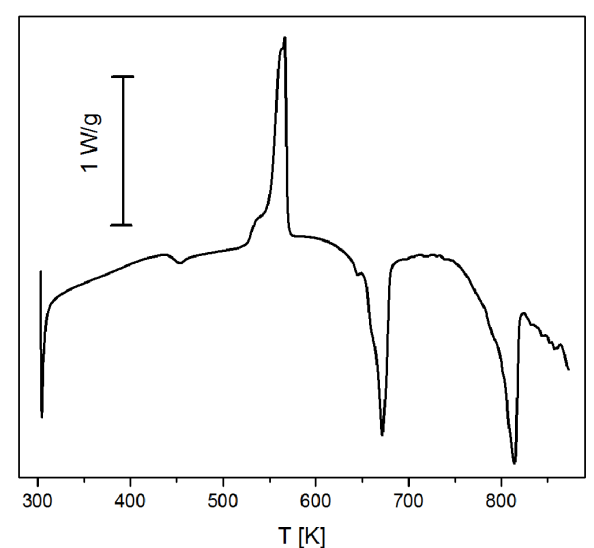

Fig. 10. Control recording of $\mathrm{Sb}_{37} \mathrm{~S}_{48} \mathrm{I}_{15}$ glass.

than $700 \mathrm{~K}$. This was concluded based on the detected mass difference of the samples before and after DSC measurement. Full analysis of this process was not made in order to protect the furnace and DSC sensors from contamination. Still, a control measurement was done, with only one heating rate (see Fig. 10). As it can be seen in Fig. 10, there is an endothermic peak which corresponds to melting of the $\mathrm{Sb}_{2} \mathrm{~S}_{3}$ structural unit at expected 


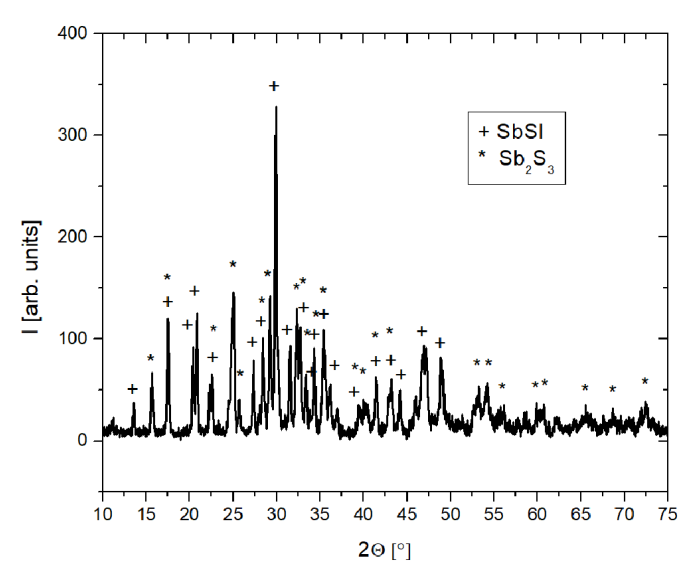

Fig. 11. XRD pattern ofSb ${ }_{37} \mathrm{~S}_{48} \mathrm{I}_{15}$ glass after annealing.

temperature. This is an indirect proof that this structural unit has indeed crystallized during the crystallization process.

Direct evidence of crystallization of structural units is the recorded XRD (see Fig. 11) of the sample annealed at the temperatures where crystallization peaks appear on DSC curves. The presence of two structural units has been confirmed according to the JCPDS 42-1393 for $\mathrm{Sb}_{2} \mathrm{~S}_{3}$ and JCPDS 21-0050 for SbSI.

\section{Conclusions}

Analysis of thermally stimulated processes by using two different isoconversional methods in $\mathrm{Sb}_{37} \mathrm{~S}_{48} \mathrm{I}_{15}$ chalcogenide glass was made. Activation energies obtained from both methods and for all detected processes are in accordance, which is an indicator of their reliability.

Apparent activation energy change with the extent of conversion (temperature) for glass transition is a typical decreasing curve found in most glasses. This is related to an increase of the free volume, which enables the structural units to transit from cooperative movements together with the closest neighbors, to move freely, in non-cooperative manner.

The dynamic fragility index is also determined for the extent of conversion of 0.5 , and its value of $m=23.2(10)$ indicates that this glass does not undergo significant configuration changes near glass transition temperature.

Crystallization of $\mathrm{Sb}_{37} \mathrm{~S}_{48} \mathrm{I}_{15}$ is complex, consisting of crystallization of at least two structural units, i.e., SbSI and $\mathrm{Sb}_{2} \mathrm{~S}_{3}$. The increase of activation energy of SbSI with the extent of conversion has been explained by the influence of the initial stage of parallel crystallization of the new structural unit $\mathrm{Sb}_{2} \mathrm{~S}_{3}$. The value of activation energy of crystallization does not change significantly during the processes which is a consequence of the mechanism of crystallization characterized by crystal growth with a constant number of nucleation centers. The small changes in activation energy provide a confirmation of validity of application of different nonisoconversional methods in the analysis of crystallization mechanisms.

Isoconversional analysis of melting of crystallized SbSI structural unit has shown that it is also a complex process and not a single-step one. The activation energy change from $E_{\alpha}=526 \mathrm{eV}(\alpha=4 \%)$ to $E_{\alpha}=341 \mathrm{eV}(\alpha=96 \%)$ has been detected. The values of melting temperatures and XRD pattern of the annealed sample were the confirmation of crystallized structural units.

\section{Acknowledgments}

The authors acknowledge financial support of the Ministry of Education, Science and Technological Development of the Republic of Serbia (Grant No. 451-03-9/2021-14/200125).

\section{References}

[1] C. Quémard, F. Smektala, V. Couderc, A. Barthélémy, J. Lucas, J. Phys. Chem. Solids 62, 1435 (2001).

[2] M.D. Pelusi, V.G. Ta'eed, L. Fu, E. Magi, IEEE J. Sel. Top. Quantum Electron. 14, 529 (2008).

[3] C. Plesa, D. Turcanu, C. Todirică, I. Nicola, Chalcogenide Lett. 12, 633 (2015).

[4] S. Asokan, K. Lakshmi, J. Indian Inst. Sci. 91, 319 (2011).

[5] L. Calvez, C.R. Phys. 18, 314 (2017).

[6] K.O. Čajko, D.L. Sekulić, D.M. Sekulić, N. Ćelić, V. Labaš, M. Kubliha, S. LukićPetrović, J. Electron. Mater. 48, 6512 (2019).

[7] R. Kaplan, B. Kaplan, Acta Phys. Pol. A 135, 332 (2019).

[8] M. Ganaie, M. Zulfequar, Acta Phys. Pol. A 128, 59 (2015).

[9] L. Zhu, D. Yang, L. Wang, J. Zeng, Q. Zhang, M. Xie, P. Zhang, S. Dai, Opt. Mater. 85, 220 (2018).

[10] D. Yin, D. Tu, B. Che, F. Zhang, C. Lin, S. Dai, J. Inorg. Mater. 29, 279 (2014).

[11] K.O. Čajko, S.R. Lukić-Petrović, G.R. Štrbac, T.B. Ivetić, Acta Phys. Pol. A 129, 509 (2016).

[12] A. Andreev, Z. Borisova, E. Bichkov, Y. Vlasov, J. Non-Cryst. Solids 35-36, 901 (1980).

[13] E.A. Zhilinskaya, V.N. Lazukin, E.A. Bychkov, I.L. Likholit, J. Non-Cryst. Solids 119, 263 (1990). 
[14] H. Kim, W.H. Lee, J.H. Lee, D.K. Kwon, Y.S. Song, Y.G. Choi, Ceram. Int. 45, 12010 (2019).

[15] M. Šiljegović, S. Lukić-Petrović, D. Petrović, I. Videnović, I. Turyanytsa, Acta Phys. Pol. A 129, 488 (2016).

[16] A. Yang, M. Zhang, L. Li, Y. Wang, J. Am. Ceram. Soc. 99, 12 (2016).

[17] E.R. Shaaban, H.A. Elshaikh, M.M. Soraya, Phys. Pol. A 128, 358 (2015).

[18] L.X. Qin, X.C. Pan, F.Q. Song et al., Appl. Phys. Lett. 112, 032102 (2018).

[19] H. Zhang, C.X. Liu, X.L. Qi, X. Dai, Zh. Fang, Sh.Ch. Zhang, Nat. Phys. 5, 438 (2009).

[20] L. Wang, C.D. Wright, M.M. Aziz, C. Hui Yang, G. Wei Yang, Jpn. J. Appl. Phys. 53, 028002 (2014).

[21] B. Srinivasan, A. Gelle, F. Gucci, C. Boussard-Pledel, B. Fontaine, R. Gautier, J.F. Halet, M. Reece, B. Bureau, Inorg. Chem. Front. 6, 63 (2019).

[22] R. Golovchak, YA. Shpotyuk, J. Szlezak, A. Dziedzic, A. Ingram, J. Cebulski, Opt. Lett. 43, 387 (2018).

[23] P. Lucas, Z. Yang, M.K. Fah, T. Luo, S. Jiang, C. Boussard-Pledel, M.L. Anne, B. Bureau, Opt. Mater. Express 3, 1049 (2013).

[24] J.L. Adam, X. Zhang, Glasses: Preparation, Properties and Applications, Woodhead Publishing Limited, Cambridge 2014.

[25] R.J. Mehta, Y. Zhang, C. Karthik, B. Singh, R.W. Siegel, T. Borca-Tasciuc, G. Ramanath, Nat. Mater. 11, 233 (2012).

[26] C. Vautier, Solid State Phenom. 71, 249 (2000).

[27] R. Golovchak, M.J. Seage, J. Szlezak, Y. Shpotyuk, D. Płoch, F. Chevire, C. Boussard-Pledel, B. Bureau, J. Alloy. Compd. 835, 155224 (2020.

[28] D. Savytskii, M. Sanders, R. Golovchak, B. Knorr, V. Dierolf, H. Jain, J. Am. Ceram. Soc. 97, 198 (2014).

[29] E.I. Gerzanich, V.A. Lyakhovitskaya, V.M. Fridkin, B.A. Popovkin, in: Current Topics in Materials Science, Ed. E. Kaldis, North-Holland Publishing, Amsterdam 1982 , p. 55 .
[30] E. Fatuzzo, G. Harbeke, W.J. Merz, R. Nitsche, H. Roetschi, W. Ruppel, Phys. Rev. 127, 2036 (1962).

[31] G.E. Vinogradova, Stakloobrazovaniye $i$ fazovyravnovetsiya $v$ halkogenidskikh sistemakh, Izdatelstvo Nauka, Moscow 1984 (in Russian).

[32] I.D. Turyanitsa, B.M. Koperles, Neorg. Mater. 9, 851 (1973) (in Russian).

[33] T.D. Tran, D.L. Sidebottom, J. Am. Ceram. Soc. 96, 2147 (2013).

[34] G.R. Štrbac, S.R. Lukić-Petrović, D.D. Strbac, D.M. Petrović, J. NonCryst. Solids 358, 1146 (2012).

[35] G.R. Štrbac, F. Skuban, S.R. Lukić, D.D. Štrbac, J. Optoelectron. Adv. Mater. 9, 1690 (2007).

[36] C.A. Angell, D.R. Macfarlane, M. Oguni, Ann. NY Acad. Sci. 484, 241 (1986).

[37] C.A. Angell, Science, 267, 1924 (1995).

[38] M. Brown, D. Dollimore, A. Galwey, Reactions in the Solid State in series Comprehensive Chemical Kinetics, Vol. 22, Elsevier, Amsterdam 1980

[39] J. Šsták, Ber. Bunsen. Phys. Chem. 12D, 721 (1985).

[40] H. Kissinger, Anal. Chem. 29, 1702 (1957).

[41] T. Akahira, T. Sunose, Res. Report Chiba Inst. Technol. 16, 22 (1971).

[42] A. Coats, J. Redfern, Nature 201, 68 (1964).

[43] S. Vyazovkin, J. Comput Chem. 22, 178 (2001).

[44] S. Vyazovkin, D. Dollimore, Chem. Inf. Comput. Sci. 36, 42 (1996).

[45] V.M. Gorbachev, J. Therm. Anal. 8, 349 (1975).

[46] F. Skuban, S.R. Lukić, D.M. Petrović, I. Guth, G.R. Štrbac, J. Optoelectron. Adv. Mater. 9, 3100 (2007).

[47] M. Abu El-Oyoun, Mater. Chem. Phys. 131, 495 (2011).

[48] S. Vyazovkin, Isoconversional Kinetics of Thermally Stimulated Processes, Springer Int. Pub., Switzerland 2015.

[49] Handbook of Chemistry and Physics, Ed. C. Weast, CRC Press, USA 1974. 